\title{
Article \\ Self-Renewal of Invasive Goldenrods (Solidago spp.) as a Result of Different Mechanical Management of Fallow
}

\author{
Dorota Gala-Czekaj *(1), Agnieszka Synowiec $(\mathbb{1})$ and Teresa Dąbkowska \\ Department of Agroecology and Crop Production, Faculty of Agriculture and Economics, University of \\ Agriculture in Kraków, Mickiewicza 21, 31-120 Krakow, Poland; agnieszka.synowiec@urk.edu.pl (A.S.); \\ teresa.dabkowska@urk.edu.pl (T.D.) \\ * Correspondence: dorota.gala@urk.edu.pl
}

Citation: Gala-Czekaj, D.;

Synowiec, A.; Dąbkowska, T.

Self-Renewal of Invasive Goldenrods (Solidago spp.) as a Result of Different Mechanical Management of Fallow.

Agronomy 2021, 11, 1065.

https://doi.org/10.3390/

agronomy11061065

Academic Editor: Donato Loddo

Received: 31 March 2021

Accepted: 17 May 2021

Published: 25 May 2021

Publisher's Note: MDPI stays neutral with regard to jurisdictional claims in published maps and institutional affiliations.

Copyright: (c) 2021 by the authors Licensee MDPI, Basel, Switzerland. This article is an open access article distributed under the terms and conditions of the Creative Commons Attribution (CC BY) license (https:/ / creativecommons.org/licenses/by/ $4.0 /)$.

\begin{abstract}
The spread of invasive plants is one of the most significant causes of biodiversity loss in natural, semi-natural, and anthropogenic habitats in Poland. This two-year study aimed to assess the rate of self-renewal of Canadian goldenrod (Solidago canadensis L.) and giant goldenrod (S. gigantea Aiton), and the possibility of achieving full generative development on fallow land restored to agricultural use with mechanical treatments. The following research objects were examined: the control (no mechanical treatments); one-time mowing; two-time mowing; one-time mowing plus onetime rotary tilling; and one-time mowing plus two-time rotary tilling. The phenological development of Solidago spp. was observed every 14 days from June to September each year. In October of each growing season, the aboveground parts of goldenrods' biomass were measured, and selected morphological parameters were assessed. Two-time mowing and one-time mowing with two-time rotary tilling resulted in the highest reductions in the share of goldenrods in the generative stages of development, of $64.0 \%$ and $51.7 \%$ compared to the control, respectively. The two-time mowing treatment was the most effective at inhibiting goldenrods' biomass accumulation, with a 57.7-77.0\% decrease in biomass compared to the control. This treatment also reduced the number of flowering shoots and inflorescence lengths of both Solidago species.
\end{abstract}

Keywords: Canadian goldenrod; giant goldenrod; invasive plant species; phenological development; mechanical weed control

\section{Introduction}

Canadian goldenrod (Solidago canadensis L.) and giant goldenrod (S. gigantea Aiton) are among the most invasive plant species to be found in many European countries [1,2], including Poland [3,4], Slovakia [5], the Czech Republic [6], Hungary [7,8], and Norway [9]. Invasive goldenrods also threaten biodiversity in Asia, Australia, and New Zealand [10-15].

Canadian goldenrod and giant goldenrod originated in the eastern part of North America [1,7,16,17], and were introduced to Europe as ornamental plants [18]. Over time, goldenrods began to spread wildly from cultivated sites to anthropogenic [19,20], seminatural, and natural habitats [3,20]. Today, invasive goldenrods are observed across almost all of Poland; they occur en masse in many regions of the country, occupying large areas and forming dense, often single-species communities [20-24]. They pose a major threat to native plant species, competing with them for an ecological niche and displacing them from ecosystems, resulting in decreased biodiversity of plant communities and homogenization of the landscape [2,25]. Goldenrods are considered to be a limiting factor in the biodiversity of pollinating insects [26,27] and birds in meadow habitats in central and eastern Europe, including Poland [28]. Due to the threat they present, invasive goldenrods occurring in Poland have been included in the list of species posing a threat to nature in Poland and the European Union [29].

The ecological success of the goldenrod is due, amongst other things, to a wide range of tolerance of environmental factors [23,30], excellent acclimatization to new habitat con- 
ditions [7,22], and their impact on the transformation of nutrients in the soil [31]. Kozak and Pudełko [32] stated that the fields where invasive goldenrods appeared were indicated as the fallow areas most affected by soil degradation. Ecosystems invaded by S. gigantea were found to have, among other things, lower soil $\mathrm{pH}$ and higher labile $\mathrm{P}$ fractions [33,34]. In sites invaded by S. canadensis, to those in the native sites, total soil nitrogen, total phosphorus, available phosphorus content, and aggregate stability consistently decreased [13]. Vegetative and generative reproduction, where high fertility and ease of spreading achenes play an important role, are conducive to the rapid spread of goldenrods $[9,15,35,36]$. In the initial period of colonization, propagation by achenes is of greater importance, while, in the later period, vegetative reproduction is more important [24]. Another advantage of goldenrods is their allelopathic potential [25,37-39]. In light of recent studies [40], the allelopathic potential of Canadian goldenrod may be exacerbated by drought stress. As studies conducted in China show [14], warmer and more humid bioclimatic conditions may result in the intense spread of Canadian goldenrod in the future. Ren et al. [41] have noted that invasive species have a higher chance of ecological success under conditions where nitrogen deficiency in the soil and global warming coexist. The above reports allow us to envisage a progressive threat related to the presence of invasive species of the Solidago genus in Poland, which, according to [42], will be exposed to severe atmospheric droughts in the coming decades. It is envisaged that this may affect biotopes particularly vulnerable to the encroachment of unwanted newcomers, especially those important to the preservation of biodiversity, such as protected areas [43], meadows [20,27,44,45], and riversides [20,46] or wetland habitats [47].

Numerous studies point to the widespread encroachment of invasive goldenrods on agricultural lands. Occurrence of Solidago spp. is particularly observed on extensively farmed arable lands, especially in areas that are left fallow on a long-term basis or are adjacent to fallow lands, and on roadsides and field borders [3,23,24,32,48]. For this reason, invasive goldenrods are even identified as being bioindicators of fallow lands [49]. Energy crops are also at risk of intensifying the occurrence of goldenrods [50]. In the view of Jezierska-Domaradzka and Domaradzki [48], for this reason, it is inadvisable to consider the possibility of growing invasive goldenrods for energy purposes, even though these species, which occur in dense canopies of growth, may provide significant quantities of biomass.

The attempts to restore agricultural functions to long-term fallow areas described in the literature indicate that Canadian goldenrod and giant goldenrod are some of the most burdensome and difficult-to-control perennial species $[6,8,22,24,44,51]$. The costs of removing goldenrods [52], and the efficacy and potential impact of applied methods of eliminating fallow lands - especially those based on herbicides—on other species are of significance [53]. Moreover, as studies such as [24] show, the application of herbicides does not give lasting results in eliminating goldenrods, which show a significant degree of regrowth a few months after treatment. The use of mechanical methods for limiting the growth of goldenrods, especially during the early stages of colonization of endangered habitats, could be an interesting alternative, due to the negative environmental impact of methods based on the application of herbicides, as well as the impossibility of destroying undesirable species on protected lands with herbicides selectively.

This study aimed to (1) assess the course of the developmental phases, and (2) assess the aboveground biomass, of Canadian goldenrod and giant goldenrod during the selfrenewal of plant cover on post-agricultural fallow restored by mechanical treatments of varying intensity.

\section{Materials and Methods}

\subsection{Research Area}

A field experiment was conducted in the growing seasons of 2015-2016. The study's location was on post-agricultural fallow land in Kraków-Mydlniki ( $50^{\circ} 08^{\prime} 74^{\prime \prime}$ E, $19^{\circ} 86^{\prime} 59^{\prime \prime} \mathrm{N}$; southern Poland). The research area was permanently covered with dense canopies of 
both species of invasive goldenrods (heterogeneous mosaic of S. canadensis and S. gigantea). The land had not been used for agricultural purposes for around 10 years. Apart from the dominant goldenrods, the following species or genera of trees and shrubs, typical for fallow lands in advanced stages of secondary succession, occurred: walnut (Juglans regia L.), black cherry (Prunus serotina Ehrh.), birch (Betula sp. L.), and dog rose (Rosa canina L.). In the growing season before the start of the experiment, the study area was cleared of self-seeded trees and shrubs; their aboveground parts were cut back, and their underground parts were dug up and removed. In the first year of the study, the fallow land was divided into five research objects in three repetitions. Due to the limited area of clustered goldenrods, it was decided to keep the larger areas for research on plots subjected to mechanical treatments. All of the plots, except for the controls, had a surface area of $8 \mathrm{~m}^{2}$ ( $4 \mathrm{~m}$ long and $2 \mathrm{~m}$ wide); the control plots had a surface area of $4 \mathrm{~m}^{2}$ ( $2 \mathrm{~m}$ long and $2 \mathrm{~m}$ wide). The experiment was set up in a random block layout.

\subsection{Soil-Weather Conditions}

The experiment was located on Luvisols [54]. The representative soil samples were sampled from a 0-20 cm layer using an Egner's cane, according to the Polish Standard PNR-04031:1997. Soil properties were determined at the Regional Chemical and Agricultural Station's accredited laboratory in Kraków (Accreditation No. 759). The soil contained $41.07 \%$ sand, $54.14 \%$ silt, and $4.79 \%$ clay. The soil $\mathrm{pH}$ in $\mathrm{KCl}$ was 5.5 . Organic matter content was $1.93 \%$, total nitrogen was $1.11 \%$, available phosphorus $\left(\mathrm{P}_{2} \mathrm{O}_{5}\right)$ was $3.4 \mathrm{mg} / 100 \mathrm{~g}^{-1}$ of soil, available potassium $\left(\mathrm{K}_{2} \mathrm{O}\right)$ was $13.5 \mathrm{mg} / 100 \mathrm{~g}^{-1}$ of soil, and available magnesium $(\mathrm{Mg})$ was $7.2 \mathrm{mg} / 100 \mathrm{~g}^{-1}$ of soil.

Weather data-i.e., the mean air temperature and sums of precipitation in the years of the study-were obtained from the meteorological station at the Kraków-Mydlniki Experimental Station of the University of Agriculture. For long-term data, the mean temperature and sums of precipitation for Kraków were used [55].

The first year of the study was characterized by a slightly higher average air temperature for the growing season (April-October) than the second year of the study (Table 1).

Table 1. Mean air temperature $\left({ }^{\circ} \mathrm{C}\right)$ for 10 -days periods, months, and growing seasons in the years 2015-2016, and over the long-term period, in Kraków-Mydlniki.

\begin{tabular}{cccccccccc}
\hline \multirow{2}{*}{ Year } & \multirow{2}{*}{ 10-Days Period } & \multicolumn{7}{c}{ Month } \\
\cline { 3 - 9 } & & IV & V & VI & VII & VIII & IX & X & IV-X \\
\hline \multirow{3}{*}{2015} & 1 & 4.2 & 13.3 & 19.1 & 21.1 & 23.3 & 15.2 & 9.5 & 15.1 \\
& 2 & 9.7 & 13.2 & 17.7 & 20.0 & 21.8 & 17.8 & 6.8 & 15.3 \\
& 3 & 12.1 & 12.6 & 15.8 & 20.7 & 19.6 & 11.9 & 6.8 & 14.2 \\
& Mean & 8.7 & 13.0 & 17.5 & 20.6 & 21.5 & 15.0 & 7.7 & 14.9 \\
\hline \multirow{2}{*}{2016} & 1 & 10.0 & 12.5 & 16.3 & 19.0 & 18.7 & 18.5 & 8.9 & 14.8 \\
& 2 & 10.3 & 11.7 & 18.1 & 18.2 & 16.6 & 16.5 & 7.4 & 14.1 \\
& 3 & 6.5 & 18.2 & 20.0 & 20.9 & 18.6 & 10.6 & 7.3 & 14.6 \\
$1951-2000$ & Mean & 9.0 & 14.1 & 18.1 & 19.4 & 18.0 & 15.2 & 7.8 & 14.5 \\
\hline & Mean & 8.0 & 13.1 & 16.4 & 17.9 & 17.3 & 13.3 & 8.4 & 13.5 \\
\hline
\end{tabular}

In 2015, the mean air temperature for the growing season was $14.9^{\circ} \mathrm{C}$, while, in 2016, it was $14.5^{\circ} \mathrm{C}$. Higher mean air temperatures were recorded in both seasons compared to the long-term period (1951-2000). The warmest month in 2015 was August, whereas it was July in 2016 and over the long-term period. The coolest month in both growing seasons was October, and over the long-term period the lowest mean air temperature was recorded in April.

The growing seasons in both years of the study differed significantly in the amount of precipitation (Table 2). 
Table 2. Sum and mean precipitation $(\mathrm{mm})$ for 10-days periods, months, and growing seasons in the years 2015-2016, and over the long-term period, in Kraków-Mydlniki.

\begin{tabular}{cccccccccc}
\hline \multirow{2}{*}{ Year } & \multirow{2}{*}{ 10-Days Period } & \multicolumn{7}{c}{ Month } \\
\cline { 3 - 9 } & & IV & V & VI & VII & VIII & IX & X & IV-X \\
\hline \multirow{3}{*}{2015} & 1 & 14.0 & 37.3 & 0.0 & 5.1 & 3.8 & 11.4 & 0.0 & 71.6 \\
& 2 & 0.8 & 20.8 & 20.8 & 23.1 & 61.0 & 29.2 & 20.3 & 176.0 \\
& 3 & 27.4 & 45.7 & 15.0 & 14.2 & 4.3 & 28.5 & 5.6 & 140.7 \\
& Sum & 42.2 & 103.9 & 35.8 & 42.4 & 69.1 & 69.1 & 25.9 & 388.4 \\
\hline \multirow{2}{*}{2016} & 1 & 14.0 & 12.7 & 25.7 & 31.0 & 74.7 & 11.2 & 77.5 & 246.8 \\
& 2 & 22.4 & 24.4 & 21.3 & 70.9 & 20.8 & 7.4 & 18.0 & 185.2 \\
& 3 & 15.5 & 8.9 & 9.4 & 78.2 & 18.3 & 1.3 & 32.0 & 163.6 \\
$1951-2000$ & Sum & 51.8 & 46.0 & 56.4 & 180.1 & 113.8 & 19.8 & 127.5 & 595.4 \\
\hline
\end{tabular}

In the 2015 growing season, only $388.4 \mathrm{~mm}$ of precipitation was recorded, while in the following season, it was as much as $595.4 \mathrm{~mm}$. The mean sum of precipitation for the growing seasons from 1951 to 2000 was $487.0 \mathrm{~mm}$. The month with the highest amount of precipitation during the growing season in the first year of the study was May, whereas in the second year and over the long-term period it was July. The lowest precipitation in the 2015 growing season and over the long-term period was recorded in October, while in 2016 it was in September.

\subsection{Mechanical Treatments}

In the experiment, the following research objects were applied: control—no mechanical treatments $(\mathrm{C})$, one-time mowing $(1 \mathrm{M})$, two-time mowing $(2 \mathrm{M})$, one-time mowing plus one-time rotary tiller treatment $(1 \mathrm{M}+1 \mathrm{RT})$, and one-time mowing plus two-time rotary tiller treatment $(1 \mathrm{M}+2 \mathrm{RT})$. The first mowing was performed in the first year on 15 May, while in the second year it was performed on 20 May. The plants were cut a second time five weeks after the first mowing, i.e., on 22 June 2015 and 28 June 2016, respectively. The plants were mowed at the surface of the soil, and their height at mowing was approximately $15 \mathrm{~cm}$. The machines used in the experiment were an Acme Motori single-axle scythe mower (ACME, Reggio Emilia, Italy) and a Muratori MZ4S 115 rotary tiller (Muratori, Modena, Italy). The mowed plants were left on the surface of the plots, discarded in a uniform layer, without further shredding. A one-time or two-time rotary tiller treatment, to a depth of ca. $15 \mathrm{~cm}$, was performed just after the first mowing of the plants on plots where those treatments were planned.

\subsection{Phenological Development Observations}

Each year, the developmental phases of goldenrods were systematically recorded in order to determine the rate of self-renewal of goldenrods subjected to the mechanical treatments, from the beginning of June to the end of September. The observations covered all treatments, and were carried out every 14 days (Table 3). The first observation was conducted three weeks after the first mechanical treatment. Due to their similarities in morphological structure, biology, and ecology, no distinction was made in the observations between the goldenrod species.

Five phases of goldenrods' development were distinguished, based on [56], including two phases of vegetative development: (1) emergence and early vegetation, and (2) development of shoots; and three phases of generative development: (3) formation of inflorescences, (4) flowering, and (5) fruiting and shedding of achenes. Moreover, the percentage share of goldenrods in the plant cover of each plot was recorded in the individual development phases. One thousand two hundred analyses were performed (four treatments + control $\times$ three repetitions $\times$ eight observation periods $\times$ five development phases $\times$ two years) in total. 
Table 3. Dates of developmental phase observations of Solidago spp. in the years of study.

\begin{tabular}{cc}
\hline 2015 & 2016 \\
\hline June 2. & June 10. \\
June 16. & June 25. \\
June 30. & July 9. \\
July 14. & July 23. \\
July 28. & August 6. \\
August 11. & August 20. \\
August 25. & September 3. \\
September 9. & September 17. \\
\hline
\end{tabular}

\subsection{Measurements of Biomass and Biometric Parameters}

In both years, by the end of the growing season, plant material was collected from each experimental plot from two $0.5 \mathrm{~m}^{2}$ areas $\left(1 \mathrm{~m}^{2}\right.$ in total), in order to measure the size of the aboveground biomass of goldenrods, and to determine the inflorescence parameters of individual specimens that achieved generative development. The aboveground parts of goldenrods were separated from the aboveground parts of accompanying weeds, and the fresh mass of both groups of plants was measured. In the first year, the measurement of biomass was taken on 2 October, while in the second year it was taken on 18 October. In each sample, the number of goldenrod shoots with inflorescence was counted. Twenty shoots of Solidago spp. were then randomly taken, and their length with inflorescence and the length of their inflorescences were determined. In the second growing season, the number of inflorescence branches was counted on twenty goldenrod shoots.

\subsection{Statistical Analysis}

An introductory, descriptive part of the analysis was performed for the percentage share of the goldenrods only, using MS Excel spreadsheets (Figures 1-5 and accompanying comments).

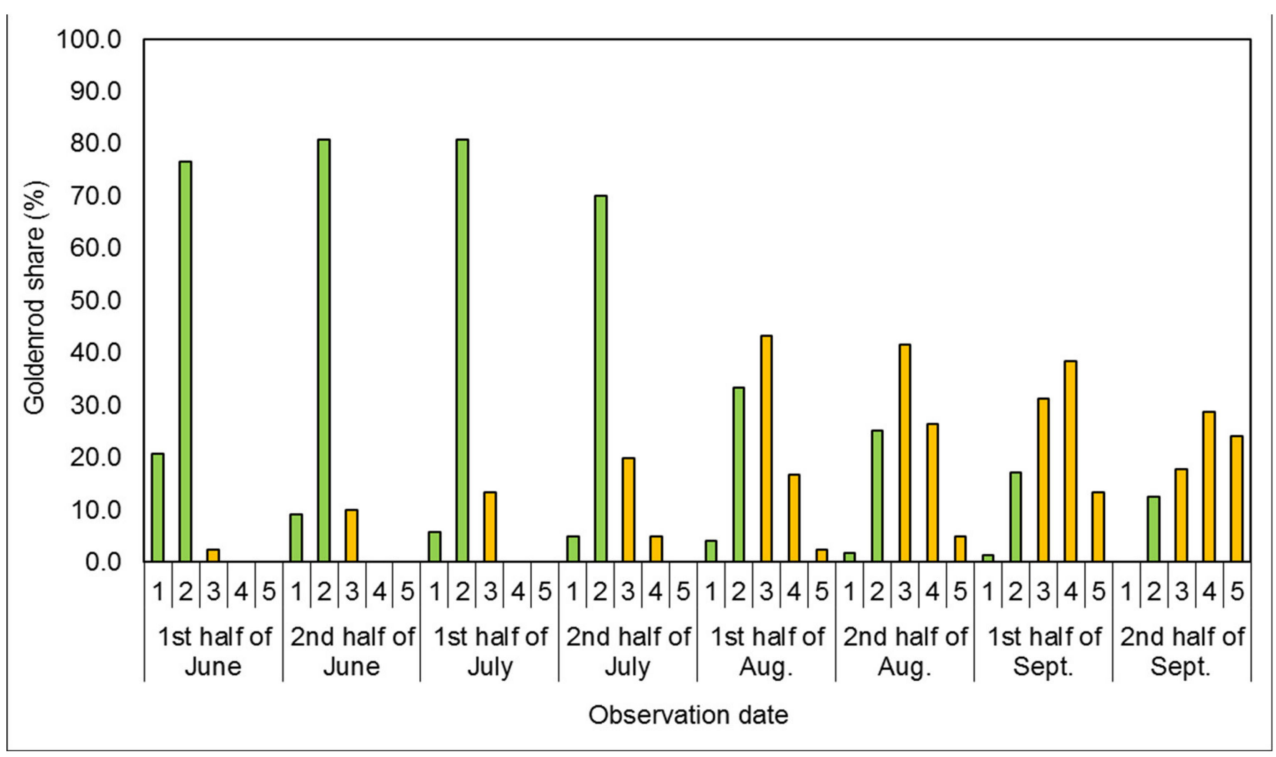

Figure 1. Mean share of goldenrods in successive developmental stages covering the plots' surfaces in the control treatment (C). In Figures 1-5, vegetative stages are marked green, while generative stages are orange, and the numbers mark the successive stages of the goldenrods' development: (1) emergence and early vegetation, (2) development of shoots, (3) formation of inflorescences, (4) flowering, and (5) fruiting and shedding of achenes. 


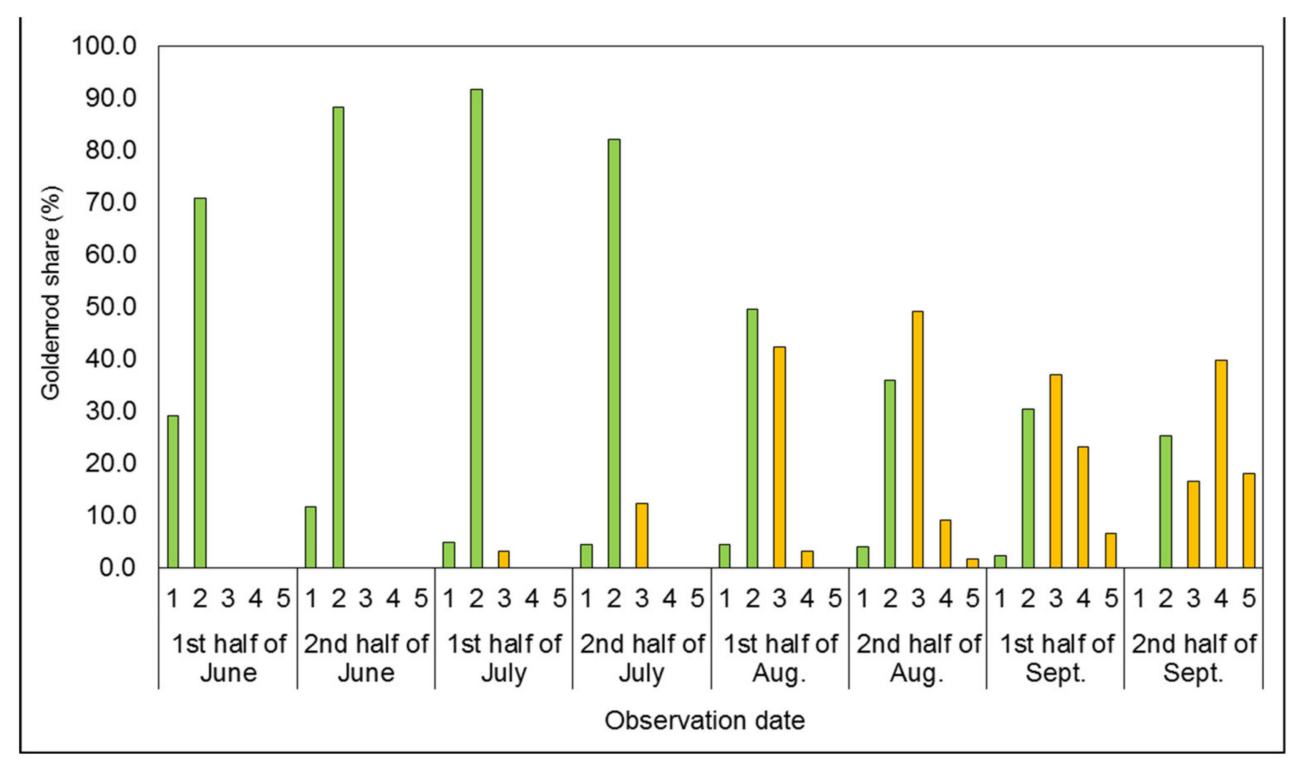

Figure 2. Mean share of goldenrods in successive developmental stages covering the plots' surfaces in the one-time mowing treatment (1M). In Figures 1-5, vegetative stages are marked green, while generative stages are orange, and the numbers mark the successive stages of the goldenrods' development: (1) emergence and early vegetation, (2) development of shoots, (3) formation of inflorescences, (4) flowering, and (5) fruiting and shedding of achenes.

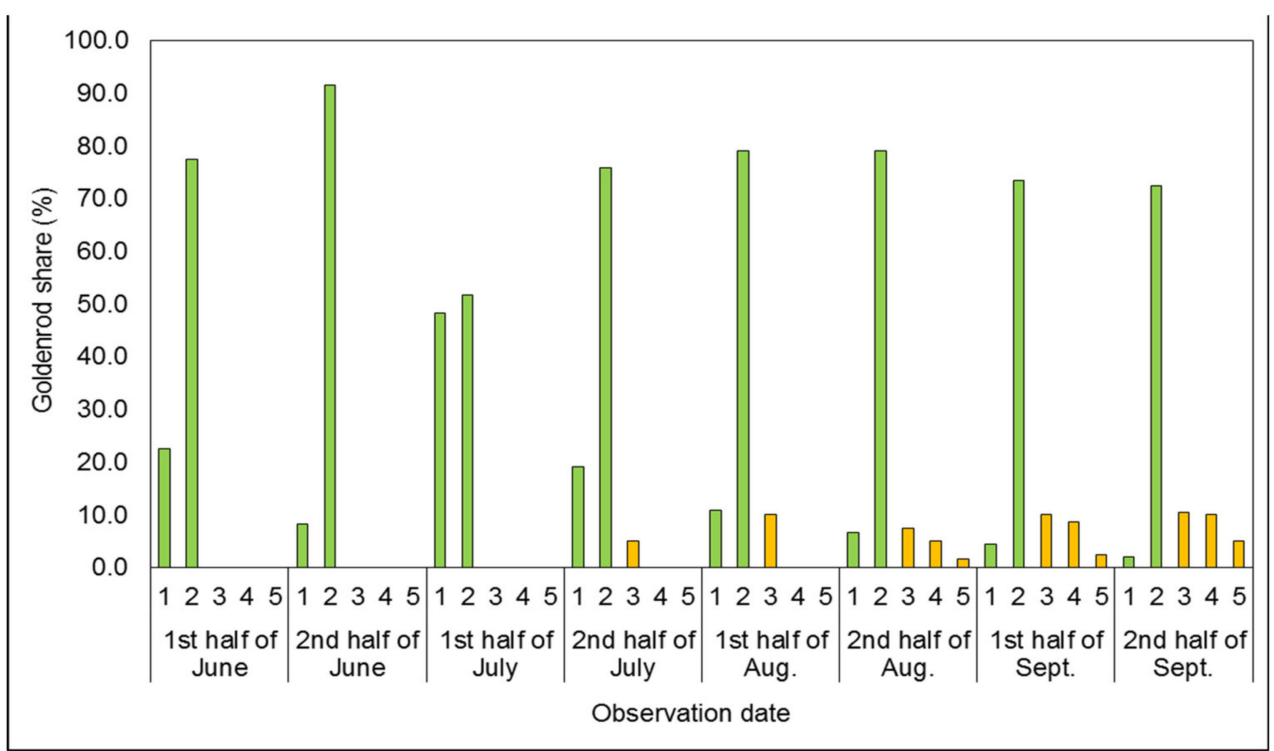

Figure 3. Mean share of goldenrods in successive developmental stages covering the plots' surfaces in the two-time mowing treatment (2M). In Figures 1-5, vegetative stages are marked green, while generative stages are orange, and the numbers mark the successive stages of the goldenrods' development: (1) emergence and early vegetation, (2) development of shoots, (3) formation of inflorescences, (4) flowering, and (5) fruiting and shedding of achenes. 


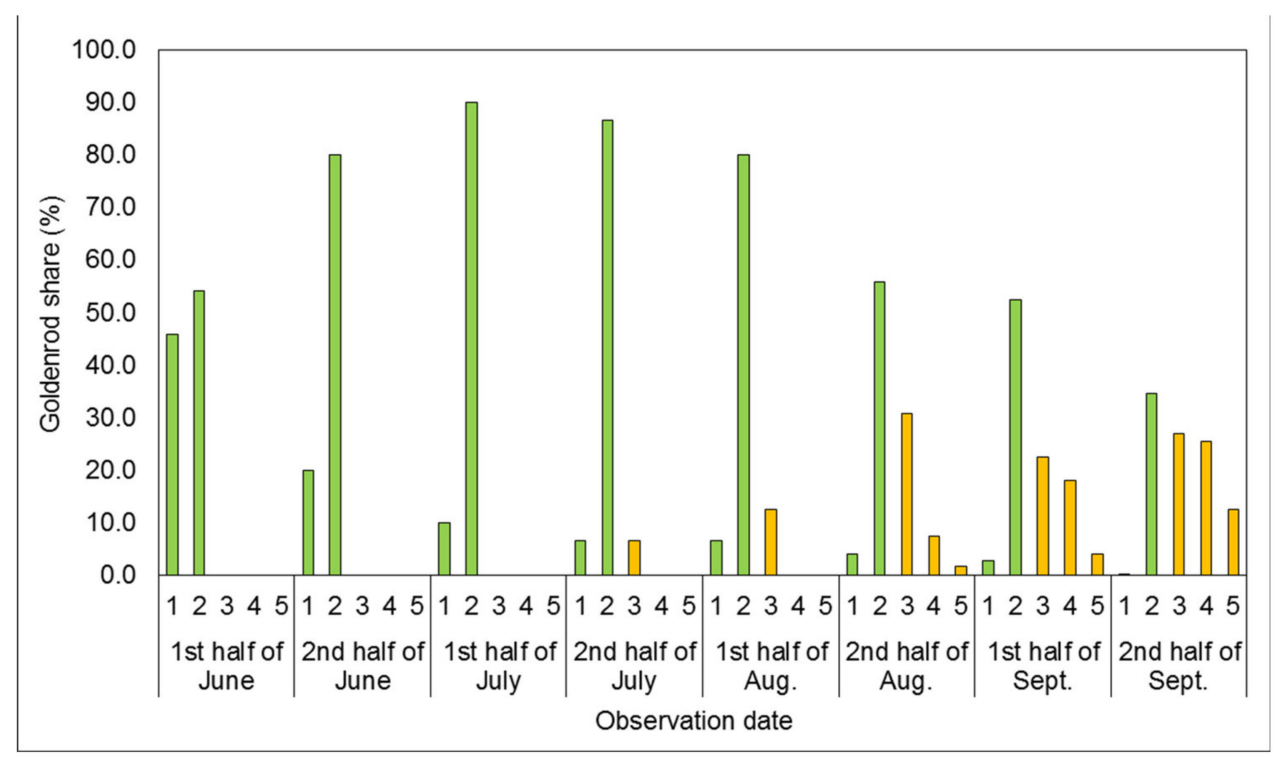

Figure 4. Mean share of goldenrods in successive developmental stages covering the plots' surfaces in the one-time mowing with one-time rotary tiller treatment $(1 M+1 R T)$. In Figures $1-5$, vegetative stages are marked green, while generative stages are orange, and the numbers mark the successive stages of the goldenrods' development: (1) emergence and early vegetation, (2) development of shoots, (3) formation of inflorescences, (4) flowering, and (5) fruiting and shedding of achenes.

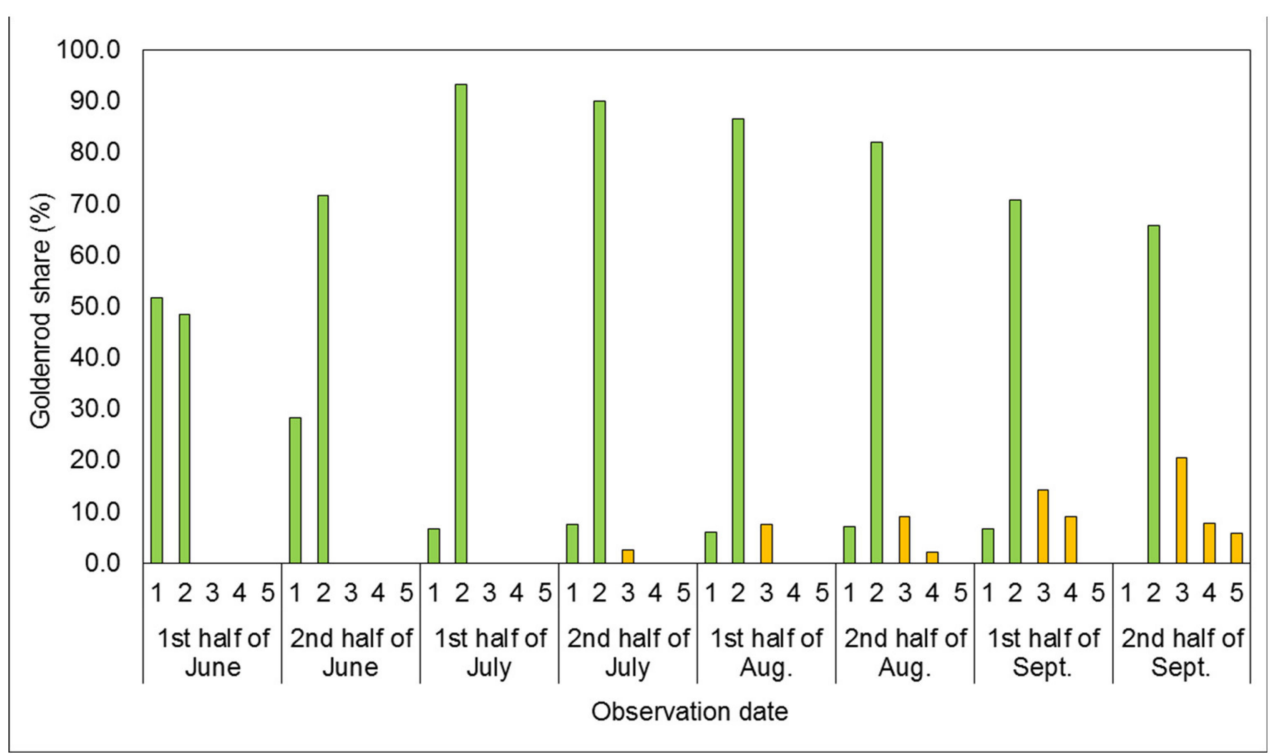

Figure 5. Mean share of goldenrods in successive developmental stages covering the plots' surfaces in the one-time mowing with two-time rotary tiller treatment $(1 M+2 R T)$. In Figures 1-5, vegetative stages are marked green, while generative stages are orange, and the numbers mark the successive stages of the goldenrods' development: (1) emergence and early vegetation, (2) development of shoots, (3) formation of inflorescences, (4) flowering, and (5) fruiting and shedding of achenes.

For the part of the results that indicated the effectiveness of the mechanical treatments and were statistically significant, general linear models (GLM) were applied using Statistica 13.3 (TIBCO Software Inc., Tulsa, OK, USA). In the analysis of goldenrods' percentage shares, the treatment, observation date, and developmental stage (vegetative and generative) were used as predictors. In the case of goldenrods' biomass, their aboveground length, and the number of shoots with inflorescences, the only independent factor was the treatment. 


\section{Results}

\subsection{Phenological Development Observations}

The mechanical treatments of varying intensity had a variable impact on the selfrenewal rate of invasive goldenrods (Figures 1-5).

In the control treatment $(\mathrm{C})$, on the first four observation dates (from the first half of June to the second half of July), individual specimens in the stages of vegetative development were dominant in the plant cover of plots. The percentage of plants in the emergence and early vegetation stage was the highest in the first observation term (the first half of June), amounting to approximately $20 \%$, and decreasing until the complete disappearance of individual specimens in that stage upon the last observation (the second half of September). From the beginning of June to the end of July, goldenrods in the shoot development stage represented the largest share of plant cover, amounting to $70.0-80.0 \%$. At the same time, in the first observation term, an approximately $2.5 \%$ share of Solidago spp. individuals in the formation of inflorescences stage was recorded. The first flowering individuals were found in the second half of July, while individuals in the fruiting and shedding of achenes stage were found two weeks later. From the first half of August to the second half of September, nearly two-thirds of the population achieved generative development-approximately $62.0-83.0 \%$, depending on the date of observation. In the last observation term (the second half of September), nearly $25.0 \%$ of plants were already in the stage of fruiting and shedding of achenes.

In the treatment with one-time mowing (1M; Figure 2), the initial development of the goldenrods was similar to that of the control (cf. Figure 1).

The treatment did not significantly limit the rate of vegetative development of Solidago spp. Until the first observation (the first half of June), over $70.0 \%$ of regrowing plants successfully developed shoots. On the next three dates of observation, the share of individuals in the development of shoots stage was approximately $90.0 \%$. The first individuals in the formation of inflorescences stage were observed in the first half of July, which was four weeks later than in the control treatment. In the $1 \mathrm{M}$ treatment during the next observations, there was also a slight slowing down in the rate of goldenrods' development, with a lower share of plants in the various stages of generative development than in the control treatment. As a result, the beginning of the flowering and the fruiting and shedding of achenes stages were two weeks delayed compared to the control treatment. The first flowering individuals were observed as late as the first half of August, and their share was only $3.3 \%$. In turn, the first fruiting and shedding achenes individuals appeared two weeks later. The delay in the development of the goldenrods was thus reflected in a lower share of individuals reaching full maturity and shedding achenes in the last observation. The share of plants capable of shedding achenes amounted to $18.2 \%$, and was ca. 7 percentage points (p.p.) less than in the control treatment.

The first two observations of the two-time mowing treatment (2M; Figure 3) were analogous to those obtained for the one-time mowing treatment (cf. Figure 2). The majority of individuals-i.e., 77.5-91.7\%—in the 2M treatment achieved the development of shoots stage by the end of June. In the first half of July, a similar 50.0\% share of plants was recorded in the emergence and early vegetation stage and the development of shoots stage. As a result, the first individuals forming inflorescences were recorded only in the second half of July 2015. A two- and six-week delay in reaching the generative stages was observed compared to the $1 \mathrm{M}$ and control treatments, respectively. Plants in the fruiting and shedding of achenes stage were recorded only in the second half of August 2015, with a $5.0 \%$ share by the end of the growing season. In the second year of the study, in the $2 \mathrm{M}$ treatment, goldenrods remained in the stage of shoot development to the end of the growing season (Figure 3).

The development of plants treated with the one-time mowing plus one-time rotary tiller treatment $(1 \mathrm{M}+1 \mathrm{RT}$; Figure 4$)$ was also delayed compared to the control treatment (cf. Figure 1). 
In the first analysis observation term, in the first half of June, $45.2 \%$ of goldenrod individuals were found to be in the emergence and early vegetation stage, and $54.2 \%$ in the development of shoots stage. On the next two observation dates, the goldenrods development was almost identical to that in the control and $1 \mathrm{M}$ treatments, except that no individuals were in the stage of inflorescences forming. Contrarily, in the 1M + 1RT treatment, they were noted six and two weeks later, as in the control and $2 \mathrm{M}$ treatment. The beginning of the flowering and the fruiting and shedding of achenes stages in the $1 \mathrm{M}$ $+1 \mathrm{RT}$ treatment was two weeks later than in the control and $1 \mathrm{M}$ treatments. On average, $12.6 \%$ of individuals capable of shedding achenes were found on the last assessment date, which was two times less than in the control treatment, but over two times more than in the two-time mowing treatment.

For the one-time mowing plus two-time rotary tiller treatment (1M + 2RT; Figure 5), the development of Solidago spp. in the period from the first half of June to the first half of August was almost identical to that in the $1 \mathrm{M}+1 \mathrm{RT}$ treatment (cf. Figure 4).

The goldenrods reached the formation of inflorescences stage approximately six weeks later compared to the control treatment. As a result, in the second half of August, there was a 20.0 p.p. lower share of individuals forming inflorescences, and 5.5 p.p. less flowering individuals, than in the $1 \mathrm{M}+1 \mathrm{RT}$ treatment, as well as no individuals shedding achenes. In the $1 \mathrm{M}+2 \mathrm{RT}$ treatment, goldenrod plants started fruiting and shedding achenes as late as in the second half of September. Moreover, their percentage was only $5.8 \%$.

The efficacy of the $2 \mathrm{M}$ and $1 \mathrm{M}+2 \mathrm{RT}$ treatments in stimulating the vegetative development and inhibiting the generative development of the goldenrods is shown in Figure 6.

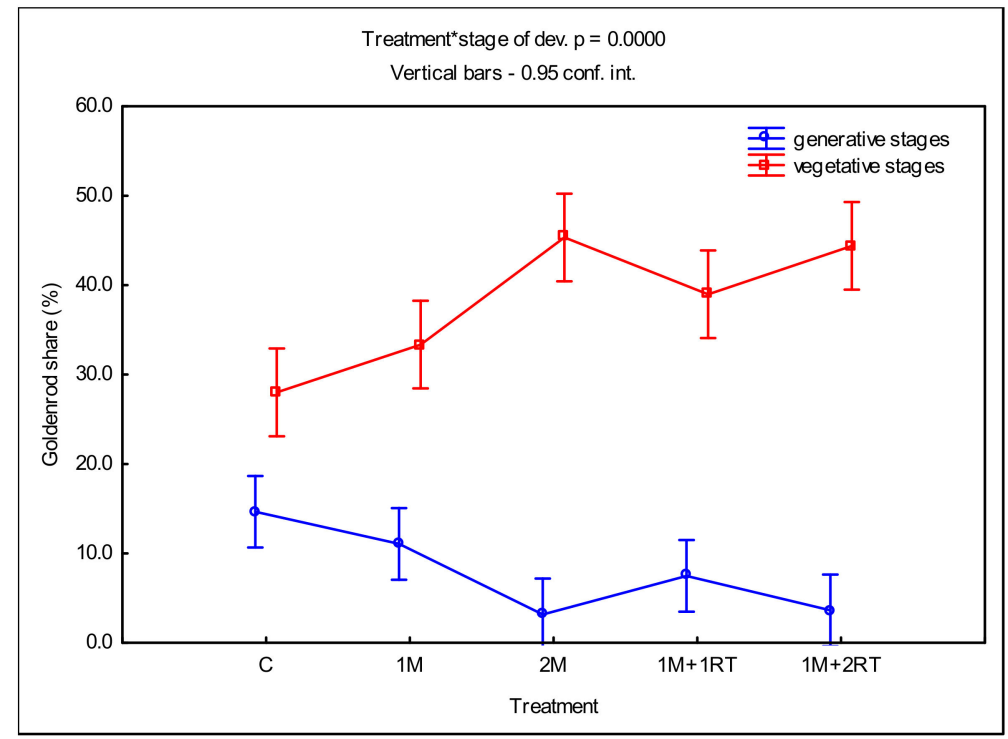

Figure 6. Mean share of goldenrods in vegetative and generative stages covering the plots' surfaces, depending on the type of mechanical treatment. The following symbols denote the research treatments: C: control; 1M: one-time mowing; 2M: two-time mowing; $1 \mathrm{M}+1 \mathrm{RT}$ : one-time mowing with one-time rotary tilling; $1 \mathrm{M}+2 \mathrm{RT}$ : one-time mowing with two-time rotary tilling.

The average share of goldenrods in the vegetative stages in the $2 \mathrm{M}$ treatment was the highest among all of the examined treatments, at $45.4 \%$. In contrast, in the stages of generative development, it was only $2.7 \%$.

\subsection{Measurements of Biomass and Biometric Parameters}

The mechanical treatments had varying impacts on the aboveground biomass of the plants (Figure 7). 


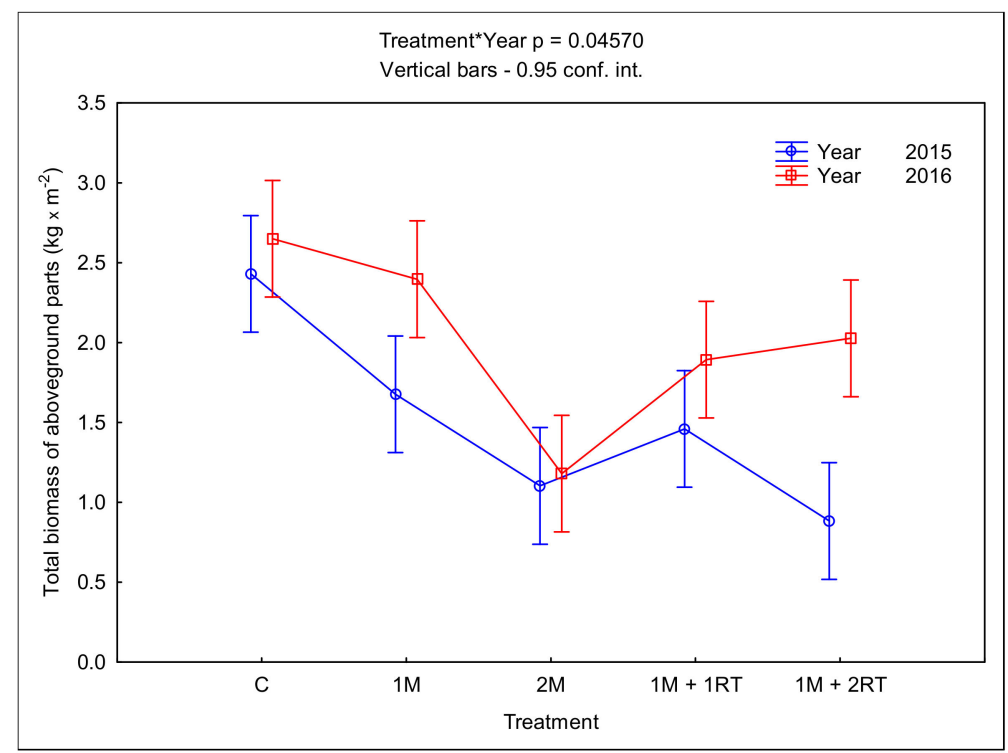

Figure 7. Mean fresh mass of the aboveground parts of plants per $1 \mathrm{~m}^{2}$, depending on the type of mechanical treatment. The following symbols denote the research treatments: C: control; $1 \mathrm{M}$ : one-time mowing; $2 \mathrm{M}$ : two-time mowing; $1 \mathrm{M}+1 \mathrm{RT}$ : one-time mowing with one-time rotary tilling; $1 \mathrm{M}+2 \mathrm{RT}$ : one-time mowing with two-time rotary tilling.

In 2015, the accumulation of aboveground biomass was limited mostly by the $1 \mathrm{M}+2 \mathrm{RT}$ treatment. The total mass of the aboveground parts of plants per $1 \mathrm{~m}^{2}$ was equal to $0.883 \mathrm{~kg} \mathrm{~m}^{-2}$-almost three times lower than in the control treatment $\left(2.430 \mathrm{~kg} \mathrm{~m}^{-2}\right)$. In the second year of the study, 2016, the efficacy of all methods in limiting the aboveground biomass of plants was lower. For example, in 2016, the 1M + 2RT treatment was less effective at limiting the accumulation of a fresh mass of the aboveground parts of plants compared to 2015. However, the most effective treatment in limiting the aboveground biomass accumulation in both years proved to be the $2 \mathrm{M}$ treatment. The fresh mass of aboveground parts for that treatment was $1.103 \mathrm{~kg} \mathrm{~m}^{-2}$ and $1.180 \mathrm{~kg} \mathrm{~m}^{-2}$ in 2015 and 2016, respectively.

The application of the $2 \mathrm{M}$ treatment also resulted in the largest limitation of goldenrods' biomass accumulation, compared to the control treatment (Figure 8).

The fresh mass of goldenrods in the $2 \mathrm{M}$ treatment was $0.801 \mathrm{~kg} \mathrm{~m}^{-2}$ in 2015 and $0.540 \mathrm{~kg} \mathrm{~m}^{-2}$ in 2016, while in the control treatment it was 1.892 and $2.348 \mathrm{~kg} \mathrm{~m}^{-2}$ in 2015 and 2016, respectively. In addition, the average share of goldenrod biomass in the biomass of all plants in the $2 \mathrm{M}$ treatment ranged from $45.0 \%$ to $72.2 \%$, whereas in the control it was $77.4-88.7 \%$, in 2015 and 2016, respectively (cf. Figure 7). In the first year of the study, the combination of $1 \mathrm{M}+2 \mathrm{RT}$ was also highly effective; thus, the aboveground parts of the goldenrods' biomass only slightly exceeded $0.520 \mathrm{~kg} \mathrm{~m}^{-2}$ (Figure 8 ). In the second year of the study, similar to the aboveground biomass of all plants, the treatments were less effective at limiting the growth of mass of the aboveground parts of Solidago. Once again, the $1 \mathrm{M}$ treatment was the least effective at inhibiting the biomass of plants; after this treatment, the fresh mass of aboveground parts of goldenrods was 1.414 and $2.189 \mathrm{~kg} \mathrm{~m}^{-2}$ in the first and second year of the study, respectively.

The $2 \mathrm{M}$ treatment was most effective at reducing the length of the aboveground parts of the goldenrods, irrespective of the year of the study (Figure 9). 


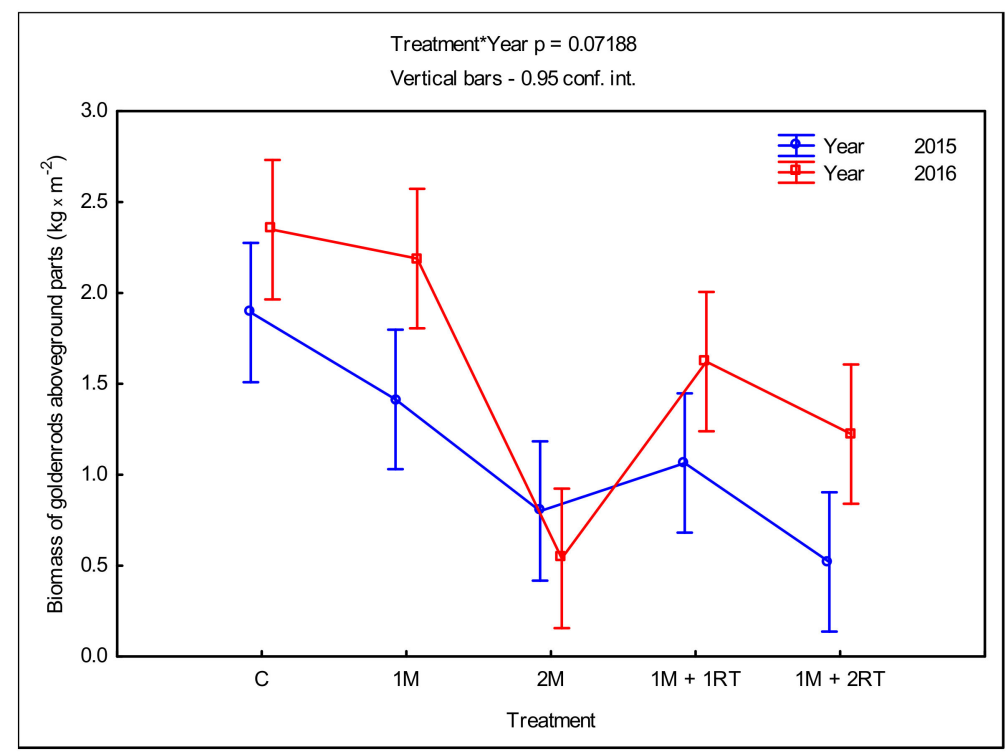

Figure 8. Mean fresh mass of the aboveground parts of goldenrods per $1 \mathrm{~m}^{2}$, depending on the type of mechanical treatment. The following symbols denote the research treatments: C: control; $1 \mathrm{M}$ : one-time mowing; $2 \mathrm{M}$ : two-time mowing; $1 \mathrm{M}+1 \mathrm{RT}$ : one-time mowing with one-time rotary tilling; $1 \mathrm{M}+2 \mathrm{RT}$ : one-time mowing with two-times rotary tilling.

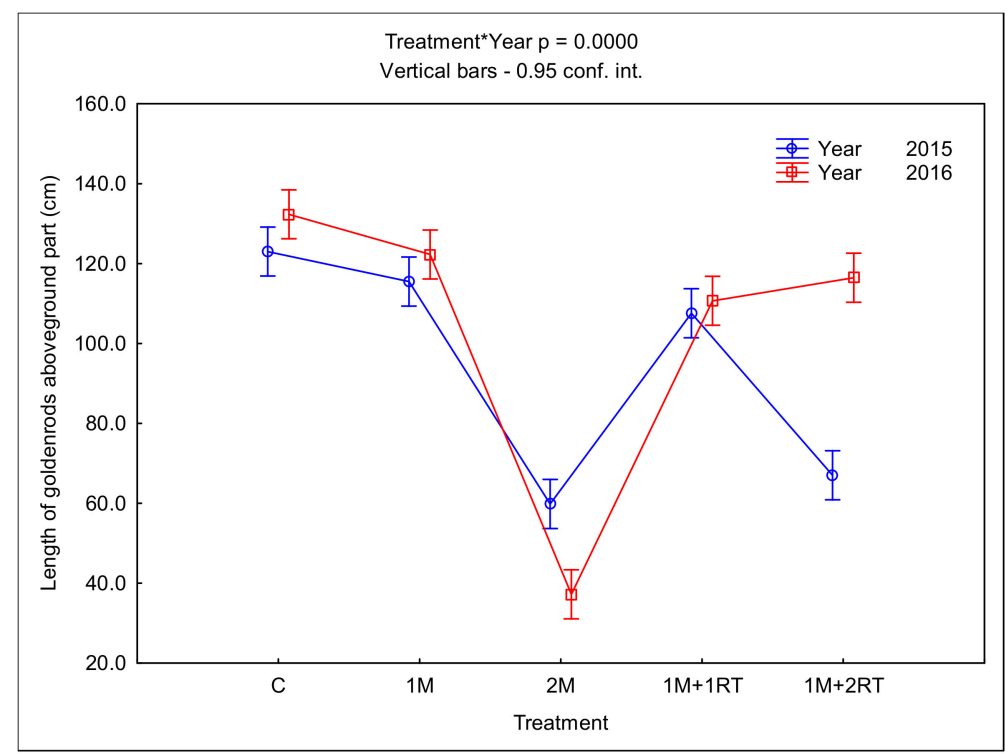

Figure 9. Mean length of the aboveground parts of goldenrods, depending on the type of mechanical treatment. The following symbols denote the research treatments: C: control; $1 \mathrm{M}$ : one-time mowing; 2M: two-time mowing; $1 \mathrm{M}+1 \mathrm{RT}$ : one-time mowing with one-time rotary tilling; $1 \mathrm{M}+2 \mathrm{RT}$ : one-time mowing with two-times rotary tilling.

The average length of the aboveground parts of goldenrods in the $2 \mathrm{M}$ treatment was $59.8 \mathrm{~cm}$ in the first year of the study and $37.2 \mathrm{~cm}$ in the second year, while in the control treatment it was $123.0 \mathrm{~cm}$ and $132.3 \mathrm{~cm}$, respectively. In 2015, the high efficacy of the $1 \mathrm{M}+2 \mathrm{RT}$ treatment was also noted; the average length of the aboveground parts of the goldenrods then was $67.0 \mathrm{~cm}$. In both years, in the $1 \mathrm{M}$ and $1 \mathrm{M}+1 \mathrm{RT}$ treatments, the length of the aboveground parts of the goldenrods was only a few $\mathrm{cm}$ less than the control treatment (Figure 9).

The number of goldenrod flowering shoots also varied depending on the mechanical treatments (Figure 10). 


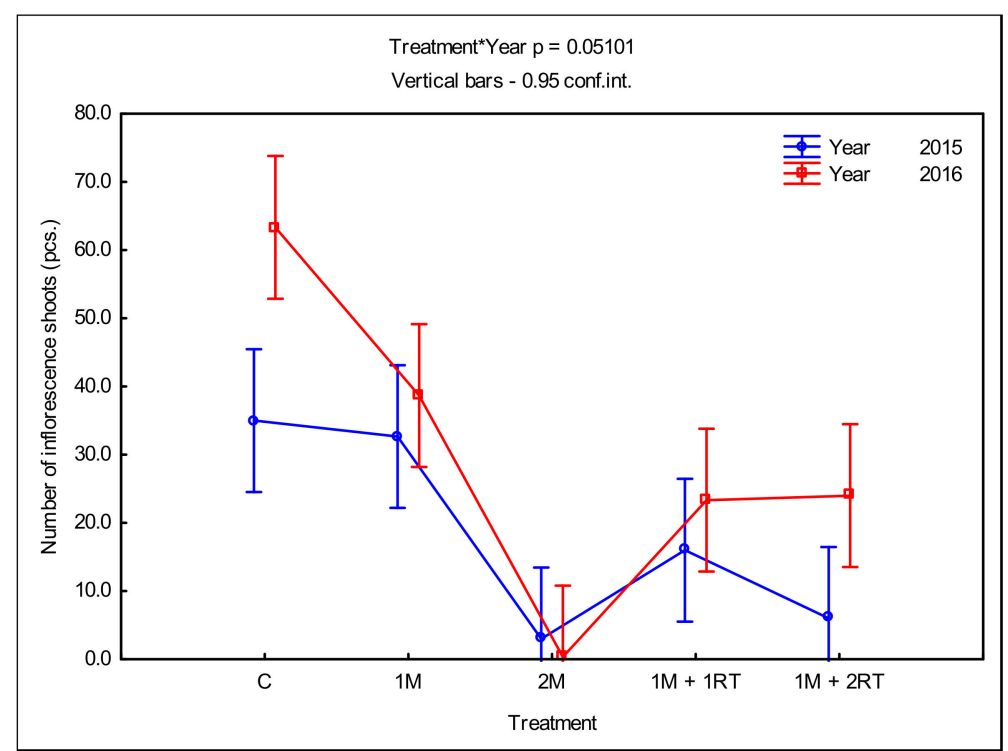

Figure 10. Mean number of goldenrod shoots with inflorescences per $1 \mathrm{~m}^{2}$, depending on the type of mechanical treatment. The following symbols denote the research treatments: C: control; $1 \mathrm{M}$ : one-time mowing; $2 \mathrm{M}$ : two-time mowing; $1 \mathrm{M}+1 \mathrm{RT}$ : one-time mowing with one-time rotary tilling; $1 \mathrm{M}+2 \mathrm{RT}$ : one-time mowing with two-times rotary tilling.

In the $2 \mathrm{M}$ treatment in 2015 , there were only three flowering shoots of goldenrods, while in the second year all plants ended their growth in the vegetative stages. The $1 \mathrm{M}+2 \mathrm{RT}$ treatment was satisfactory in reducing the number of flowering shoots per unit of the area in 2015 only. There were only 6 flowering shoots in that treatment, while in the control treatment, there were 35 of them (Figure 10).

The $2 \mathrm{M}$ treatment also reduced the average length of inflorescences (Figure 11), which was only $2 \mathrm{~cm}$ in 2015; in the second year of the study, the plants did not form inflorescences. In comparison, in the control treatment, the length of inflorescences was 25.7 and $28.2 \mathrm{~cm}$ in the first and second years, respectively. The $1 \mathrm{M}+2 \mathrm{RT}$ treatment satisfactorily reduced the length of goldenrods' inflorescences in 2015 only.

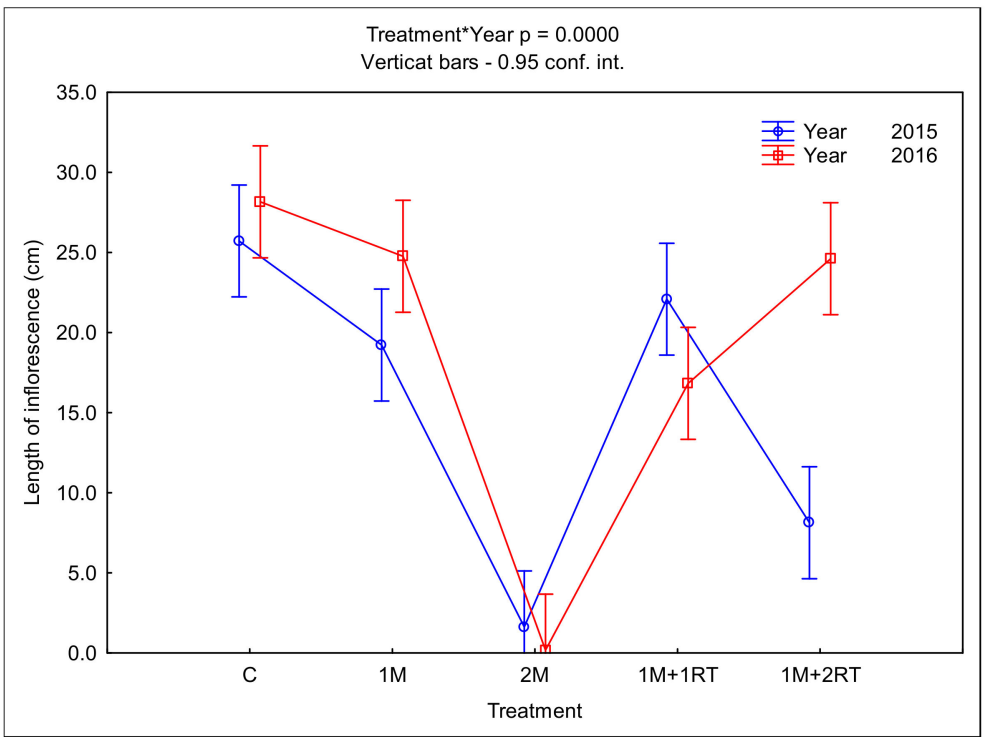

Figure 11. Mean length of goldenrod inflorescences, depending on the type of mechanical treatment. The following symbols denote the research treatments: C: control; $1 \mathrm{M}$ : one-time mowing; $2 \mathrm{M}$ : two-time mowing; $1 \mathrm{M}+1 \mathrm{RT}$ : one-time mowing with one-time rotary tilling; $1 \mathrm{M}+2 \mathrm{RT}$ : one-time mowing with two-times rotary tilling. 
Similarly, the 2M treatment reduced the number of inflorescence branches on a single goldenrod shoot, as measured in 2016 (Figure 12), as the plants did not fully form inflorescences (cf. Figure 11).

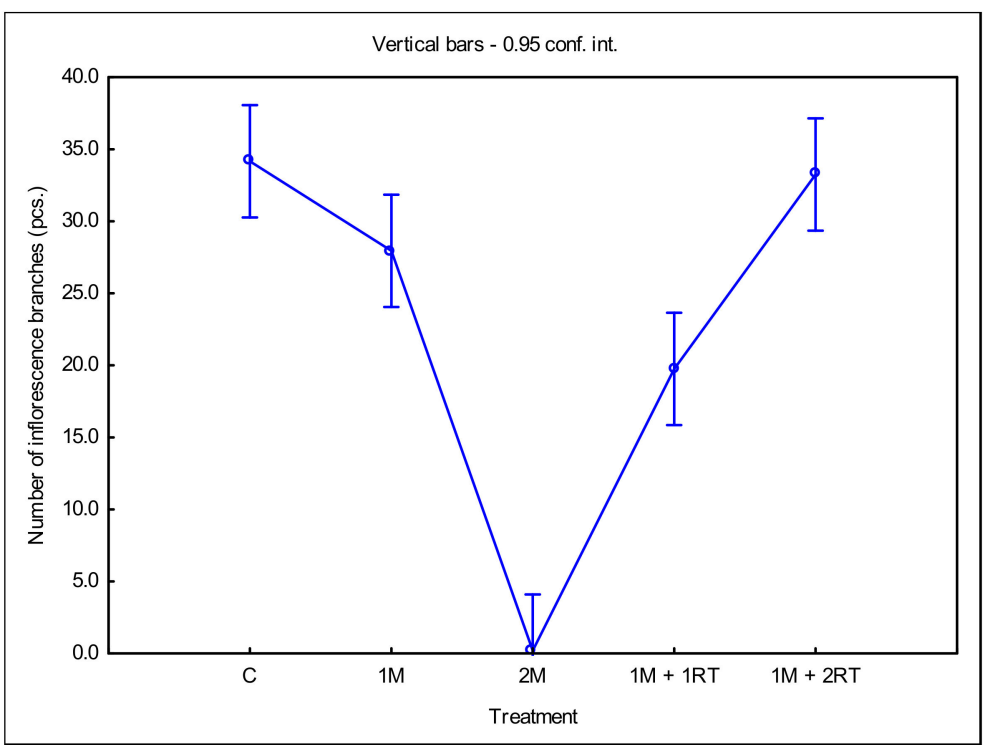

Figure 12. Mean number of inflorescence branches per single goldenrod shoot, depending on the type of mechanical treatment. The following symbols denote the research treatments: C: control; $1 \mathrm{M}$ : one-time mowing; $2 \mathrm{M}$ : two-time mowing; $1 \mathrm{M}+1 \mathrm{RT}$ : one-time mowing with one-time rotary tilling; $1 \mathrm{M}+2 \mathrm{RT}$ : one-time mowing with two-times rotary tilling.

In the case of the $1 \mathrm{M}+2 \mathrm{RT}$ treatment, the inflorescence branches were reduced by 14 units compared to the control treatment. In the control treatment, on average, 30 branches were found per inflorescence.

\section{Discussion}

Limiting the area and density of invasive goldenrods' stands opens the way for restoring natural plant cover to renew habitats. Although the most efficient method of controlling goldenrod is the chemical one $[11,22,44,57]$, herbicides pose toxicological and ecological threats, especially toward non-target organisms [53]. Biological control of goldenrods may reduce negative ecological impacts, but until now this approach has only been applied to control S. canadensis in China [58,59]. For that reason, other authors advise mechanical methods; however, they are mostly combined with herbicides [6,24].

Some authors point out that regular mowing of the goldenrods' biomass could also be the first step in restoring such areas to their natural biodiversity [48]. In our study, the one-time mowing treatment proved to be least effective at inhibiting the growth and development of goldenrods. Our results are consistent with many authors [6,51,60], who also underline that a one-time mowing treatment does not sufficiently limit the spread of goldenrods. Contrarily, [8] showed that in both the short-term (1-2 years) and the long-term (8-20 years), one-time mowing resulted in a statistically significant reduction in the density of $S$. gigantea per unit of area. Furthermore, [8] states that in the long-term experiment, in treatments where one-time mowing was carried out in June, a significant increase in the richness of species and habitat biodiversity was observed.

In our study, in the two-time mowing treatment performed in the second year, the goldenrods ended their development in the vegetative shoots stage; this is evidence of this treatment's efficacy at limiting goldenrods' development. Our finding is supported by $[16,17]$, who discovered that the two-time mowing treatment resulted in a significant reduction in biomass and limited the area occupied by invasive goldenrods. Moreover, we found that the two-time mowing treatment reduced the number of shoots ending 
with an inflorescence and the length of the inflorescences, which is important in reducing their reproductive potential and the possibility of colonizing new areas. Furthermore, supplementing mowing with a rotary tiller, especially when tilling was performed twice, effectively delayed the generative development of goldenrods, and limited the share of individuals that reached the flowering and fruiting stage. To our knowledge, this is the first finding of the effect of mechanical treatments on the generative development of goldenrods. Similarly to our results, [56] proved that two-time mechanical hoeing in maize inter-rows caused a shift in the development of Echinochloa crus-galli (L.) P.Beauv., delaying its fruiting and shedding of grains stage.

The dominance of the Solidago taxa in plant communities contributes to a reduction in the species richness, thus reducing the biodiversity of the habitats it occupies $[2,8,48]$. This finding is supported by our results concerning shifts in plants' biomass per unit of area. In the treatment without mechanical intervention, nearly all of the collected biomass consisted of goldenrods, while the remaining plant species only accounted for a very slight fraction. Applying mechanical treatments of different intensities increased the biomass of other species accompanying goldenrods in the regenerating plant cover, which shows that the treatments contributed to increasing floral diversity in the restored area. Moreover, we argue that the mechanical treatments created conditions conducive to the intrusion of species, which may originate from diaspora stimulated to sprouting from the local seed bank or spread from neighboring areas. Studies such as [60] support this claimthe authors assessed the impact of soil-turning treatments combined with undersown grasses on the density and surface cover of Canadian goldenrod. They found a reduction of approximately $42-96 \%$ and $40-94 \%$ in the density and surface cover, respectively, of S. canadensis compared to the control. In another study [44], rototilling caused a significant limitation of S. gigantea soil coverage by $60.0-97.5 \%$, compared to the control, and prompted the encroachment of grass and ruderal species, e.g., Festuca pratensis Huds., Vicia villosa Roth., Artemisia vulgaris L., and Scrophularia nodosa L.

\section{Conclusions}

The results of our work present the efficacy of mechanical treatments of varying intensity in controlling invasive goldenrods, as well as their impact on the vegetative and generative development of goldenrods, providing new information in these areas.

The application of all of the examined treatments for restoring fallow land to renewed agricultural use-i.e., one-time mowing, two-time mowing, one-time mowing with onetime rotary tiller treatment, and one-time mowing with two-time rotary tiller treatmentdelayed the developmental stages of goldenrods compared to the control treatment. The elimination of invasive goldenrods through a combination of one-time mowing with onetime rotary tiller treatment was less effective at delaying the self-renewal of plants, whereas one-time mowing had the least impact on that process. Contrarily, the two-time mowing and the one-time mowing combined with two-time rotary tiller treatments caused the largest reduction in the share of Solidago spp. individuals in generative stages, especially the stage of fruiting and shedding of achenes. Moreover, the two-time mowing and one-time mowing with two-time rotary tiller treatments resulted in greater limitation of aboveground biomass accumulation, the number of flowering shoots per unit of area, and the length of inflorescences of goldenrods. For this reason, the proposed methods can be considered to be sufficiently effective in restoring fallow lands to use, especially in the initial stage of colonization by goldenrods, as well as in areas of natural value and wherever the use of herbicides should be limited.

Author Contributions: Conceptualization: D.G.-C. and T.D.; methodology: D.G.-C., A.S. and T.D.; formal analysis: D.G.-C., A.S. and T.D.; investigation: D.G.-C. and T.D.; writing-original draft preparation: D.G.-C., A.S. and T.D.; writing-review and editing: D.G.-C. and A.S.; supervision: T.D. and A.S. All authors have read and agreed to the published version of the manuscript. 
Funding: This research was funded by the Ministry of Education and Science of the Republic of Poland.

Conflicts of Interest: The authors declare that they have no known competing financial interests or personal relationships that could have appeared to influence the work reported in this paper.

\section{References}

1. Weber, E. Current and potential ranges of three exotic goldenrods (Solidago) in Europe. Conserv. Biol. 2001, 15, 122-128. [CrossRef]

2. Jakobs, G.; Weber, E.; Edwards, P.J. Introduced plants of the invasive Solidago gigantea (Asteraceae) are larger and grow denser than conspecifics in the native range. Divers. Distrib. 2004, 10, 11-19. [CrossRef]

3. Tokarska-Guzik, B. The Establishment and Spread of Alien Plants Species (Kenophytes) in the Flora of Poland; University of Silesia: Katowice, Poland, 2005; p. 192.

4. Tokarska-Guzik, B.; Dajdok, Z.; Zając, M.; Zając, A.; Urbisz, A.; Danielewicz, W.; Hołdyński, C. The Plants of Foreign Origin in Poland with Particular Regard to Invasive Species; Generalna Dyrekcja Ochrony Środowiska: Warsaw, Poland, $2012 ;$ p. 197. (In Polish)

5. Končeková, L.; Zahradníková, E.; Pintér, E.; Halmová, D. Assessment of an impact of mechanical regulation on selected morphometric and productive parameters of invasive species Solidago canadensis population in agricultural land. Agriculture 2015, 61,121-128. [CrossRef]

6. Rajdus, T.; Svehlakova, H.; Plohak, P.; Stalmachova, B. Management of invasive species Solidago canadensis in Ostrava region (Czech Republic). IOP Conf. Ser. Earth Environ. Sci. 2020, 444, 012046. [CrossRef]

7. Pal, R.W.; Chen, S.; Nagy, D.U.; Callaway, R.M. Impacts of Solidago gigantea on other species at home and away. Biol. Invasions 2015, 17, 3317-3325. [CrossRef]

8. Nagy, D.U.; Rauschert, E.S.J.; Henn, T.; Cianfaglione, K.; Stranczinger, S.; Pal, R.W. The more we do, the less we gain? Balancing effort and efficacy in managing the Solidago gigantea invasion. Weed Res. 2020, 60, 232-240. [CrossRef]

9. Rosef, L.; Ingebrigtsen, H.H.; Heegaard, E. Vegetative propagation of Solidago canadensis—Do fragment size and burial depth matter? Weed Res. 2020, 60, 132-141. [CrossRef]

10. Weber, E. Invasive Plant Species of the World: A Reference Guide to Environmental Weeds; CABI Publishing: Oxon, UK, $2003 ;$ p. 581.

11. Shen, G.-H.; Yao, H.-M.; Guan, L.-Q.; Qian, Z.-G.; Ao, Y.-S. Distribution and infestation of Solidago canadensis L. in Shanghai suburbs and its chemical control. Acta Agric. Shanghai 2005, 21, 1-4.

12. Mei, D.; Jian-Zhong, L.; Wen-Ju, Z.C.; Bo, L. Canada goldenrod (Solidago canadensis): An invasive alien weed rapidly spreading in China. Acta Phytotax. Sin. 2006, 44, 72-85.

13. Zhang, C.B.; Wang, J.; Quin, B.Y.; Li, W.H. Effects of the invader Solidago canadensis on soil properties. Appl. Soil Ecol. 2009, 43, 163-169. [CrossRef]

14. Xu, Z.; Peng, H.; Feng, Z.; Abdulsalih, N. Predicting current and future invasion of Solidago canadensis: A study from China. Pol. J. Ecol. 2014, 62, 263-271. [CrossRef]

15. Dong, M.; Lu, B.R.; Zhang, H.B.; Chen, J.K.; Li, B. Role of sexual reproduction in the spread of an invasive clonal plant Solidago canadensis revealed using intersimple sequence repeat markers. Plant Spec. Biol. 2006, 21, 13-18. [CrossRef]

16. Weber, E. Biological flora of Central Europe: Solidago altissima L. Flora 2000, 195, 123-134. [CrossRef]

17. Weber, E.; Jakobs, G. Biological flora of central Europe: Solidago gigantea Ation. Flora 2005, 200, 109-118. [CrossRef]

18. Hitchmough, J.; De la Fleur, M.; Findlay, C. Establishing North American prairie vegetation in urban parks in Northern England. Part 1. Effect of sowing season, sowing rate and soil type. Landsc. Urban. Plan. 2004, 66, 75-90. [CrossRef]

19. Walck, J.L.; Baskin, J.M.; Baskin, C.C. Relative competitive abilities and growth characteristics of a narrowly endemic and geographically widespread Solidago species (Asteraceae). Am. J. Bot. 1999, 86, 820-828. [CrossRef]

20. Popiela, A.; Łysko, A.; Sotek, Z.; Ziarnek, K. Preliminary results of studies on the distribution of invasive alien vascular plant species occurring in semi-natural and natural habitats in NW Poland. Biodivers. Res. Conserv. 2015, 37, 21-35. [CrossRef]

21. Szymura, M.; Szymura, T.H. Distribution of goldenrods (Solidago spp.) in Lower Silesia and their impact on biodiversity of invaded vegetation. Acta Botanica Silesiaca 2011, 6, 195-212. [CrossRef]

22. Domaradzki, K.; Badowski, M. Possibility of chemical reduction of Solidago gigantea Aiton occurrence on fallow lands. Zesz. Nauk. UP Wroc. Rol. C 2012, 584, 17-24. (In Polish)

23. Pużyńska, K.; Stokłosa, A.; Stupnicka-Rodzynkiewicz, E. The impact of ecological conditions on Solidago sp. occurrence. Zesz. Nauk. UP Wroc. Rol. C 2012, 584, 89-98. (In Polish)

24. Domaradzki, K.; Jezierska-Domaradzka, A.; Badowski, M.; Matkowski, A. Occurrence and the possibility of late goldenrod (Solidago gigantea Aiton) control. Prog. Plant Prot. 2018, 58, 209-215. (In Polish)

25. Abhilasha, D.; Quintana, N.; Vivanco, J.; Joshi, J. Do allelopathic compounds in invasive Solidago canadensis s.l. restrain the native European flora? J. Ecol. 2008, 96, 993-1001. [CrossRef]

26. Fenesi, A.; Vágási, C.I.; Beldean, M.; Földesi, R.; Kolcsár, L.-P.; Shapiro, J.T.; Török, E.; Kovács-Hostyánszki, A. Solidago canadensis impacts on native plant and pollinator communities in different-aged old fields. Basic Appl. Ecol. 2015, 16, 335-346. [CrossRef]

27. Moroń, D.; Lenda, M.; Skórka, P.; Szentgyörgyi, H.; Settele, J.; Wojciechowski, M. Wild pollinator communities are negatively affected by invasion of alien goldenrods in grassland landscapes. Biol. Conserv. 2009, 142, 1322-1332. [CrossRef] 
28. Skórka, P.; Lenda, M.; Tryjanowski, P. Invasive alien goldenrods negatively affect grassland bird communities in Eastern Europe. Biol. Conserv. 2010, 143, 856-861. [CrossRef]

29. Tokarska-Guzik, B.; Bzdęga, K.; Nowak, T.; Urbisz, A.; Węrzynek, B.; Dajdok, Z. Proposed List of Alien Plant Species that May Pose a Threat to the Nature of Poland and the European Union; University of Silesia: Katowice, Poland, 2015; p. 178. (In Polish)

30. Bielecka, A.; Królak, E.; Biardzka, E. Habitat conditions of Canadian goldenrod in a selected region of Eastern Poland. J. Ecol. Eng. 2017, 18, 76-81. [CrossRef]

31. Ye, X.-Q.; Yan, Y.-N.; Wu, M.; Yu, F.-H. High capacity of nutrient accumulation by invasive Solidago canadensis in a coastal grassland. Front. Plant Sci. 2019, 10, 575. [CrossRef] [PubMed]

32. Kozak, M.; Pudełko, R. Impact assessment of the long-term fallowed land on agricultural soils and the possibility of their return to agriculture. Agriculture 2021, 11, 148. [CrossRef]

33. Chapuis-Lardy, L.; Vanderhoeven, S.; Dassonville, N.; Koutika, L.-S.; Meerts, P. Effect of the exotic invasive plant Solidago gigantea on soil phosphorus status. Biol. Fertil. Soils 2006, 42, 481-489. [CrossRef]

34. Herr, C.; Chapuis-Lardy, L.; Dassonville, N.; Vanderhoeven, S.; Meerts, P. Seasonal effect of the exotic invasive plant Solidago gigantea on soil pH and P fractions. J. Plant Nutr. Soil Sci. 2007, 170, 729-738. [CrossRef]

35. Szymura, M. Evaluation of ability for generative and vegetative reproduction of goldenrods occurred in Poland. Zesz. Nauk. UP Wroc. Rol. C 2012, 585, 103-112. (In Polish)

36. Szymura, M.; Szymura, T.H. The dynamics of growth and flowering of invasive Solidago species. Steciana 2015, 19, 143-152. [CrossRef]

37. Bing-Yao, S.; Jian-Zhong, T.; Zhi-Gang, W.; Fu-Gen, G.; Ming-De, Z. Allelopathic effects of extracts from Solidago canadensis L. against seed germination and seedling growth of some plants. J. Environ. Sci. 2006, 18, 304-309.

38. Yang, R.Y.; Mei, L.X.; Tang, J.J.; Chen, X. Allelopathic effects of invasive Solidago canadensis L. on germination and growth of native Chinese plant species. Allelopath. J. 2007, 19, 241-248.

39. Baličević, R.; Ravlić, M.; Živković, T. Allelopathic effect of invasive species giant goldenrod (Solidago gigantea Ait.) on crops and weeds. Herbologia 2015, 15, 19-29. [CrossRef]

40. Wu, R.; Wu, B.; Cheng, H.; Wang, S.; Wie, M.; Wang, C. Drought enhanced the allelopathy of goldenrod on the seed germination and seedling growth performance of lettuce. Pol. J. Environ. Stud. 2021, 30, 423-432. [CrossRef]

41. Ren, G.; He, M.; Li, G.; Anandkumar, A.; Dai, Z.; Zou, C.B.; Hu, Z.; Ran, Q.; Du, D. Effects of Solidago canadensis invasion and climate warming on soil net N mineralization. Pol. J. Environ. Stud. 2020, 29, 3285-3294. [CrossRef]

42. Pokojski, W. Drought hazard in Poland and climatic water balance. Prace Stud. Geogr. 2015, 57, 103-110. (In Polish)

43. Kirpluk, I.; Bomanowska, A. The occurrence of alien species in the settlement areas of the Kampinos National Park and its vicinity (Central Poland). Biodivers. Res. Conserv. 2015, 39, 79-90. [CrossRef]

44. Świerszcz, S.; Szymura, M.; Wolski, K.; Szymura, T.H. Comparison of methods for restoring meadows invaded by Solidago species. Pol. J. Environ. Stud. 2017, 26, 1251-1258. [CrossRef]

45. Brzank, M.; Piekut, K.; Dabrowski, P.; Pawluśkiewicz, B. The succession and regression of plant species on lowland hay meadows in Poland. Pol. J. Environ. Stud. 2019, 28, 1567-1577. [CrossRef]

46. Frelich, M.; Bzdęga, K. Management of invasive plant species in the valley of the River Slepiotka in Katowice-The example of the REURIS project. Environ. Soc. Econ. Stud. 2014, 2, 26-37. [CrossRef]

47. Nowak, A.; Kacki, Z. Species from goldenrod genus-Solidago sp. In Invasive Plant Species in Polish Wetland Ecosystems; Dajdok, Z., Pawlaczyk, P., Eds.; Klub Przyrodników: Świebodzin, Poland, 2009; pp. 80-86. (In Polish)

48. Jezierska-Domaradzka, A.; Domaradzki, K. Solidago canadensis L. as a potential energy plant-The risk to the environment and the estimation of natural raw material resources in the chosen fallow fields in Wołów County (Lower Silesia). Zesz. Nauk. UP Wroc. Rol. C 2012, 584, 43-52. (In Polish)

49. Rola, J.; Rola, H. Solidago spp. as bioindicator of fallow occurrence on arable area. Fragm. Agron. 2010, 27, 122-131. (In Polish)

50. Feledyn-Szewczyk, B.; Matyka, M.; Staniak, M. Comparison of the effect of perennial energy crops and agricultural crops on weed flora diversity. Agronomy 2019, 9, 695. [CrossRef]

51. Szépligeti, M.; Kun, R.; Bartha, S.; Bodonczi, L.; Szentirmai, I. Experience gained from the control of giant goldenrod in the Örség National Park. In Practical Experiences in Invasive Alien Plant Control, 2nd ed.; Csiszár, Á., Korda, M., Eds.; Duna-Ipoly National Park Directorate: Budapest, Hungary, 2017; pp. 135-139.

52. Szymura, M.; Szymura, T.H.; Wolski, K. Invasive Solidago species: How large area do they occupy and what would be the cost of their removal? Pol. J. Ecol. 2016, 64, 25-34. [CrossRef]

53. Boutin, C.; Strandberg, B.; Carpenter, D.; Mathiassen, S.K.; Thomas, P.J. Herbicide impact on non-target plant reproduction: What are the toxicological and ecological implications? Environ. Pollut. 2014, 185, 295-306. [CrossRef] [PubMed]

54. IUSS Working Group World Reference Base. World Reference Base for Soil Resources 2014, Update 2015-International Soil Classification System for Naming Soils and Creating Legends for Soil Maps; Report No. 106; FAO: Rome, Italy, 2015.

55. Woś, A. The Climate of Poland in the Second Half of the 20th Century; Adam Mickiewicz University: Poznań, Poland, $2010 ;$ p. 489. (In Polish)

56. Dabkowska, T.; Stupnicka-Rodzynkiewicz, E.; Bintsanga-Malounguidi, P. The effect of weather conditions and weed control measures on maize weeds development, particularly on Echinochloa crusgalli. Ann. UMCS Sec. E Agric. 2007, 52, 117-126. (In Polish) 
57. Zhang, Y.; Yang, X.; Zhu, Y.; Li, L.; Zhang, Y.; Li, J.; Song, X.; Qiang, S. Biological control of Solidago canadensis using a bioherbicide isolate of Sclerotium rolfsii SC64 increased the biodiversity in invaded habitats. Biol. Control 2019, 139, 104093. [CrossRef]

58. Tang, W.; Kuang, J.; Qiang, S. Biological control of the invasive alien weed Solidago canadensis: Combining an indigenous fungal isolate of Sclerotium rolfsii SC64 with mechanical control. Biocontrol Sci. Technol. 2013, 23, 1123-1136. [CrossRef]

59. Yuan, G. Study on the control of Solidago canadensis by spraying metsulfuron-methyl. J. Anhui Agric. Sci. 2008, 32, 14188-14189.

60. Hartmann, E.; Schuldes, H.; Kubler, R.; Konold, W. Neophyten: Biologie, Verbreitung und Kontrolle Ausgewählter Arten; Ecomed: Landsberg, Germany, 1995; p. 301. 